\title{
ASSESSMENT AND DETECTION OF LAND COVER CHANGES IN THE SOUTHERN FRINGE OF KOLKATA USING REMOTELY SENSED DATA
}

\author{
Sushobhan Majumdar \\ Former Research Fellow, Department of Geography, Jadavpur University, Kolkata, India \\ *Corresponding author: sushobhan91@gmail.com \\ Received: April 02 ${ }^{\text {th }}, 2020$ / Accepted: August 9 $9^{\text {th }}, 2020$ / Published: October $1^{\text {st }}, 2020$ \\ https://DOI-10.24057/2071-9388-2020-65
}

\begin{abstract}
Continual, historical, and precise information about the land use and land cover (LULC) changes of the Earth's surface is extremely important for any kind of sustainable development program, in which LULC serves as one of the major input criteria. In this study, a supervised classification was applied to five types of Landsat images collected over time (1980, 1990, 2000, 2010 and 2015) that provided recent and historical LULC conditions for the area. Four LULC categories were identified and mapped. Post-classification comparisons of the classified images indicated that the major change consisted of barren land changing into agricultural land. This analysis revealed that substantial growth of built-up areas in the south eastern part of Kolkata over the study period resulted in significant decrease in the area of water bodies, cultivated land, vegetation and wetlands. Urban land transformation has been largely driven by large number of population and high population growth rate with rapid economic and infrastructural development like the extension of metro railway, flyovers and hence huge real estate development.
\end{abstract}

KEY WORDS: Detection of Land Use and Land Cover Change, Sustainable Development, Urban Land Transformation, Substantial Growth

CITATION: Sushobhan Majumdar (2020). Assessment And Detection Of Land Cover Changes In The Southern Fringe Of Kolkata Using Remotely Sensed Data. Geography, Environment, Sustainability, Vol.13, No 4, p. 121-132

https://DOI-10.24057/2071-9388-2020-65

Conflict of interests: The authors reported no potential conflict of interest.

\section{INTRODUCTION}

Urbanization is an inexorable process due to economic development and rapid population growth of an area. Encroachment of urban development in the agricultural areas may pose dire consequences such as land degradation and desertification (Shalaby et al. 2004). Urban growth is the movement of residential areas or commercial areas to the semi urban or rural areas. It has long been considered a sign of regional economic sustainability. Its benefits are increasingly balanced against the ecosystem impacts, including degradation of air and water quality and loss of agricultural tracts and socio-economic effects of economic disparities as well as regional disparities, social fragmentation and the cost of infrastructure (Squires2002).

The rate of population growth is very high in developing countries rather than the developed countries. The population of urban areas is expected to exceed $60 \%$ by 2030 , with $90 \%$ of the projected increase occurring in low income countries i.e. developing or under developed countries, which have urban settlements that are growing five times the rate of those in developed countries. The rapid changes of land use and cover, in the developing countries, are often characterized by rapid urban growth, land degradation, or the transformation of agricultural land to shrimp farming ensuing huge cost to the environment (Sankhala and Singh 2014). Land cover is dynamic and varies at different spatial and temporal scales (Cihlar 2000). Therefore, determining the trend and the rate of land cover conversion are necessary for the development and planning in order to develop rational land use policy. For this purpose, the temporal dynamics of remote sensing data can play an important role in monitoring and analyzing land cover changes.

Geographic Information Systems (GIS) and Remote Sensing (RS) are very powerful and cost-effective tools for assessing the spatial and temporal dynamics of LULC (Lambin, et al. 2003; Serra et al. 2008). In case of developing countries satellite data are particularly useful due to the cost and time associated with traditional survey methods (Dong et al. 1997), and these techniques have become viable alternatives to conventional survey and ground-based urban mapping methods (Jensen et al. 2004). It is also the most common data source for detection, quantification, and mapping of LULC patterns and changes because of its repetitive data acquisition, digital format suitable for computer processing, and accurate geo-referencing procedures (Chen et al. 2005; Jensen 1996; Lu et al. 2004). Satellite data provide valuable multi-temporal data on the processes and patterns of LULC change, and GIS is very much essential for mapping and analyzing the patterns of LULC (Zhang et al. 2002). Retrospective and consistent synoptic coverage from satellites is particularly useful in areas where changes have been rapid (Blodget et al. 1991).Pre and post-classification comparisons have been extensively used (Coppin et al. 2004; Singh 1989). In the pre classification approach, procedures such as image differencing (Toll et al. 1980; Cohen and 
Fiorella1998); band rationing (Eastman et al. 2005), change vector analysis (Johnson andKasischke 1998); Lu et al. 2005) vegetation index differencing (Townshend and Justice 1995).Post-classification comparisons of derived thematic quantify the different types of change. The degree of success depends upon the reliability of the maps made by image classification. Broadly speaking, large-scale changes such as mapped reasonably easily. Whereas evolutionary changes such as erosion, succession,colonization or degradation, the boundaries may be indistinct and class-labels uncertain (Foodyand Boyd 1999); Khorram et al.1999).

Change detection and monitoring by remote sensing involves the use of several multi-date images to evaluate the differences occurring in LULC between the acquisition dates of images that are due to various environmental conditions and human actions (Singh 1989). The successful use of satellite remote sensing for LULC change detection depends upon an adequate understanding of landscape features, imaging systems, and methodology employed in relation to the aim of analysis (Yang and Lo 2002). Many change detection techniques have been developed and used for monitoring changes in LULC from remotely sensed data. There are many techniques available to detect and record differences (e.g. imagedifferencing, ratios or correlation) and these might be attributable to change (Singh 1989;Stow et al. 1996; Yuan et al. 1999). However, the simpledetection of change is rarely sufficient in itself: information is generally required about theinitial and final land cover or types or land uses, the «from-to» analysis (Khorram et al.1999). Furthermore, the detection of image differences may be confused with problems inphenology and cropping, and such problems may be exacerbated by limited imageavailability and poor quality in temperate zones, and difficulties in calibrating poor images.

Change detection is useful in many applications related to land use and land cover (LULC) changes, such as shifting cultivation and landscape changes (Imbernon 1999; Serra et al. 2008), land degradation, land suitability and desertification (Adamoand Crews- Meyer 2006); Majumdar 2020); Gaoand Liu (2010), coastal change and urban sprawl (Shalaby and Tateishi 2007), urban landscape pattern change BatisaniandYarnal(2009); Dewanand Yamaguchi (2009); Longqian et al. (2009), deforestation (Schulz et al. 2010; Wyman and Stein 2010), quarrying activities (Mouflis et al. 2008), and landscape and habitat fragmentation and other cumulative changes (Munroe et al. 2005; Nagendra et al. 2006).

Accurate and up-to-date land cover change information is necessary to understanding and assessing the environmental consequences of such changes (Giri et al. 2005). While remote sensing has the capability of capturing such changes, extracting the change information from satellite data requires effective and automated change detection techniques (Roy et al. 2002). Digital change detection is the process of determining or describing changes in land cover and landuse properties based on co-registered multi-temporal remote maps go beyond simple changedetection and attempt to widespread logging or major urban development might be

sensing data. The basic premise in using remote sensing data for change detection is that the process can identify change between two or more dates that is uncharacteristic of normal variation. Numerous researchers have addressed the problem of accurately monitoring land-cover and land-use change in a wide variety of environments (Chan et al. 2001;Muchoneyand Haack (1994); Singh 1989).

In this article remote sensing and GIS techniques was applied with the aim of answering the question how the land use and land coverhas changed in RajpurSonarpurMunicpality from 1980 to 2015, 10 years interval.

\section{STUDY AREA}

RajpurSonarpur Municipality (Fig. 1) lies on the delta of the Hooghly River with a gentle slope. It is bounded in the north by the Kolkata Municipal Corporation, to the south by Baruipur Community Development (C.D.) Block, to the east and west by Sonarpur C.D. Block. This municipality is well connected with the head quarter of eastern railway of India (i.e. Sealdah station) by the different railway stations one of them (i.e. Sonarpur) is a junction station. Other important stations are Garia, Narendrapur, and Subhasgram. By these railway stations the commuters from south 24 parganas come to city for their daily work. This town is also well connected with the Eastern-Metropolitan By pass and it also provides easy connectivity from the NetajiSubhash International Airport. The Metro Railway line connects the municipality on the northern side through KaviSubhash metro station, which is also terminal station of the existing metro railway route at present time. RajpurSonarpur Municipal area is surrounded by five outfalls viz. Adi Ganga, Kurigachhi Irrigation Channel, Tolly'sNullah, Srinagar Panchanna Gram Drainage Channel, and Rania KeorapukurKhal.

Rajpur Sonarpur Municipality comprises of 37 mouzas namely Harinavi, Kodalia, Rajpur, Malancha, Mahinagar, Jagaddal, Dhamaitala, Mallikapur, Baikunthapur, Bansidharpur, Ellachi, Ukhila-Paikpara, Barhans-Fartabad, Kumrakhali, Nischintapur, Chak-Harinavi, Manikpur, Balia, Kandarpapur-Boalia, Tentulberia, Dhalua, Panchapota, Kusumba, Garagachha, Lashkarpur, SripurBagher Ghola, Boral, Rania, Paschim-Nishintapur, Sonarpur, Ghasiara, Gorkhara, Kamrabad, Noapara, Tegharia, Chowhati, Jagannathpur. Total population of this municipality is 424368 comprising 35 wards with a growth rate of 26.03 between the years 2001-2011. In comparison with the Kolkata Metropolitan Area (KMA) the population growth rate of entire KMA is 10.30 according to Census 2011. This municipality is located in the suburbs of Kolkata city which has experienced very high growth rate i.e. 26.03 per centMajumdar and Sivaramakrishnan (2020). People from the surrounding areas migrate into this area which is the major cause of high growth rate of population. In order to provide better citizen services, amenities and infrastructural services for the inhabitants of this municipality, it has been divided (Table 1) into five local offices. Those are as listed below.

Table 1. Composition of Municipal Administration in RajpurSonarpur Municipality

\begin{tabular}{|c|c|}
\hline Name of the Local Offices & Ward Number \\
\hline Garia & 1 to 7 \\
\hline Sonarpur & 8 to 15 \\
\hline Rajpur & 16 to 26 \\
\hline Mahamayatala & 27 to 31 \\
\hline Baral & 32 to 35 \\
\hline
\end{tabular}




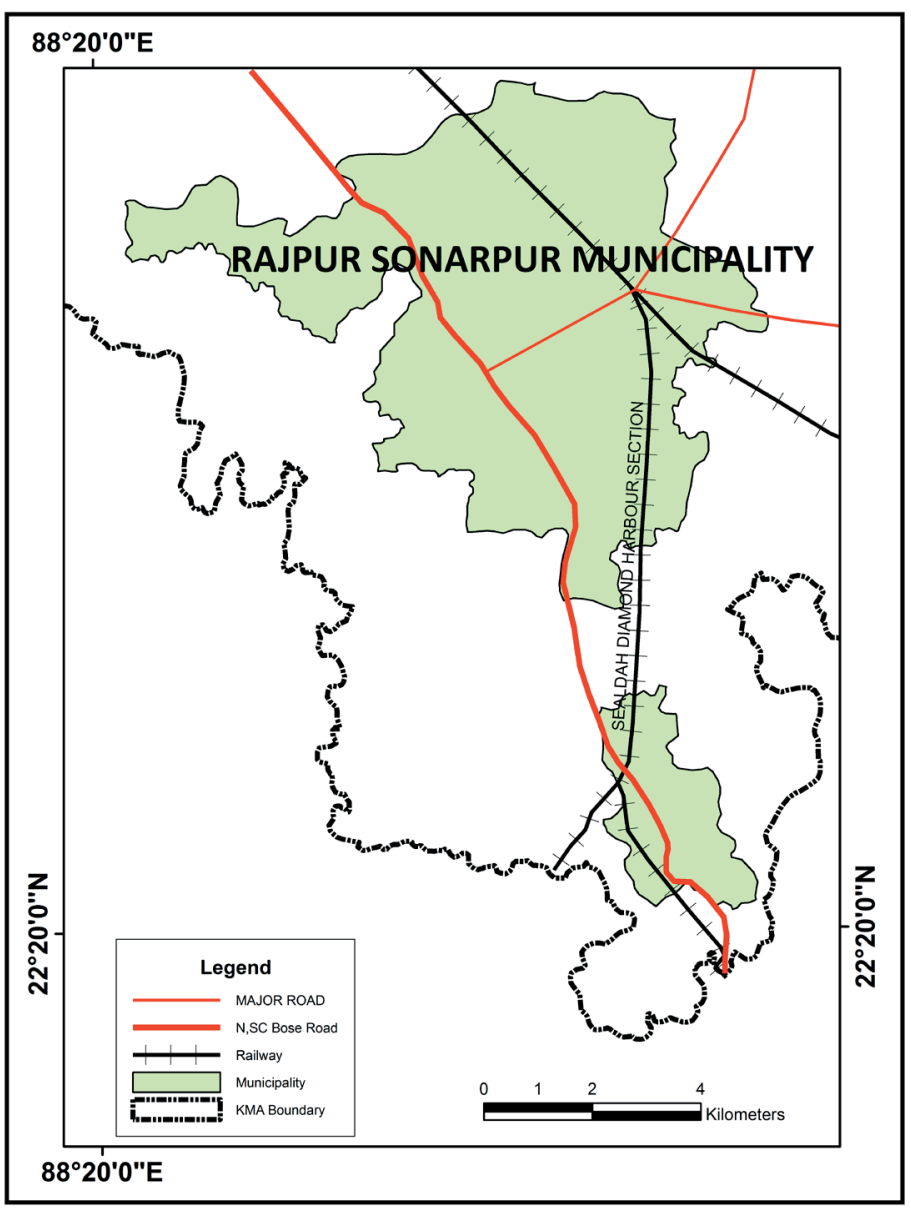

\section{MATERIAL AND METHODS}

The data set for this study is comprised of five Landsat images recorded from 1980 to 2015. Detailed description of those images discussed below (Table 2). The data has been chosen for 10 years interval because the Census of India is calculated in the interval of 10 years. By calculating 10 years interval time the researcher can easily correlate demographic characteristics (like population growth rate, density etc.) and land use land cover change of this area.

Five sets of landsat satellite images were used here. First, Landsat MSS, Landsat Thematic Mapper (TM) and Enhanced Thematic Mapper (ETM+) images and two sets of OLI 8 images (with path/row 138/45). At the time of layer stacking of those images thermal band was excluded. Digital maps published from the RajpurSonarpur Municipality, has been digitized and geo-referenced from digital topographic maps with scale of 1:50,000 which has been published by the Census of India in 2010 under the Government of India. This map has been used as a reference image only for the geometric correction and geo-referencing of the municipal area. It has also been used for geometric correction of those satellite images and to collect some ground truth information of that time period. Finally, ground information (for cross checking of the produced maps (like various types of land use and land cover information, number of water bodies or wetland in municipal area from 1980 to 2015) was collected between the years 1980 until 2015 to get land use/land cover information. Then supervised classification algorithm was used to scrutinize the land cover types.

\section{Image Processing}

The images were geometrically corrected and georeferenced to the Universal Transverse Mercator (UTM) coordinate system by using a reference image which has been geo-referenced previously by the topographical sheets which were provided by the Survey of India (SOI). This minimum of 30 randomly distributed ground control points (GCPs) were selected from the topographical sheets for geo-referencing the image. Re-sampling technique was performed using a nearest neighbour algorithm technique. Image transformation technique was used with root mean square (RMS) error of 0.1 pixels indicating that the image was accurate to within one pixel.

Table 2. Detailed Information of Utilized Satellite Imagery

\begin{tabular}{|c|c|c|c|c|}
\hline Satellite & Acquisition Date & Sensor & Spatial Resolution & Projection \\
\hline Landsat 8 & 08-03-2015 & OLI-TIRS & $30 \mathrm{~m}$ & \\
\cline { 1 - 4 } Landsat 7 & $21-01-2010$ & TM & $30 \mathrm{~m}$ & \multirow{2}{*}{ WGS 84 UTM 45 N } \\
\cline { 1 - 3 } Landsat 7 & $17-11-2000$ & ETM+ & $30 \mathrm{~m}$ & \\
\cline { 1 - 3 } Landsat 5 & $14-11-1990$ & TM & $60 \mathrm{~m}$ & \\
\hline Landsat 3 & 21-02-1980 & MSS & & \\
\hline
\end{tabular}

Source: US Geological Survey, 2015 


\section{Image Enhancement and Visual Interpretation}

Image enhancement is basically the modification of image by improving clarity and visual interpretability of the remotely sensed image. The process of visually interpreting digitally enhanced imagery attempts to optimize the complementary abilities of the human mind and the computer. The mind is excellent at interpreting spatial attributes on an image and is capable of identifying obscure or subtle features. Generally these images are used for visual analysis while original images used for automated analysis. (Lillesandand Kiefer 1994); Eastman 2006). By the process of supervised classification five land use and land cover maps were produced. Some of the classes were spectrally confused in the image of 1980 because of very low resolution of image which is MSS imagery in nature. So it could not be separated well by supervised classification. For this reason visual interpretation technique has been used to separate them properly.

\section{Image classification}

Land cover classes are typically mapped from digital remotely sensed data through the process of a supervised digital image classification (Campbell 1987; Thomas et al. 1987). The overall objective of the image classification procedure is to automatically categorize all pixels in an image into land cover classes or themes (Lillesandand Kiefer 1994). The maximum likelihood classifier has been used because it quantitatively evaluates both the variance and covariance of the category spectral response patterns when classifying an unknown pixel so that it is considered to be one of the most accurate classifier since it is based on statistical parameters.

\section{Supervised Classification}

Researcher used ERDAS IMAGINE 2014 software for digital image processing and image classification of the Landsat images described above. Training samples were selected for each of the predetermined LULC types by delimiting polygons around representative sites with the help of feature space tool. Using those polygons the researcher derived spectral signatures for the respective land cover types which are recorded on the satellite images. A spectral signature is considered to be satisfactory when confusion among the land covers to be mapped [is] minimal' (Gaoand Liu 2010). After collecting spectral signatures image classification was done using maximum likelihood as a classification method.

Maximum livelihood algorithm is one of the common parametric classifiers used for especially in case of supervised classification. This algorithm is used for computing the weighted distance or likelihood (D) of unknown measurement vector (X) belonging to one of the known classes (Mc) which is based on the Bayesian equation(Mukhopadhyay et al. 2013).

$$
D=\operatorname{In}\left(a_{c}\right)-\left[0.5 \operatorname{In}\left(\operatorname{cov}_{c}\right)\right]-\left[0.5\left(X-M_{c}\right) T\left(\operatorname{cov}_{e}-1\right)\left(X-M_{e}\right)\right]
$$

The class is assigned with the unknown measurement vector in which it has the highest probability of belonging. The advantage of maximum livelihood algorithm is that it considers the variance covariance matrix with in the class distributions.
In case of normally distributed data, this performs better than the other known parametric classifiers, though the results may be unsatisfactory for the data not having normal distributions (Mukhopadhyay et al. 2013). it may be of two types parametric and non-parametric. By the supervised classification a raster layer i.e. the classified image and a distance file originates. Both the thematic layer and the distance file were used for postclassification thresholding. Four initial LULC maps were produced. Because these are the major land use land cover types of this area (Table 3).

\section{Classification Improvement}

Some LULC classes were spectrally confused because of mixing of different colours of pixels. So it could not be properly separated by supervised classification especially in the images of 1980. For instance, confusion between the deep water bodies and wetland in some portions of the area. Because in areas of discontinuous free water bodies, significant numbers of pixels were misclassified to the fallow class due to the existence of aquatic plants which are hydrophytes in nature. To improve the level of accuracy of the classified image and to reduce misclassifications, the researcher integrated the initial LULC maps resulting from supervised classification with the maps resulting from visual interpretation. Visual interpretation was very important for increasing classification accuracy and, consequently, the quality of the LULC maps produced. In case of MSS Landsat images, due to the low resolution image correction techniques were used. Finally, the researcher produced accurate LULC maps which was also compared with the reference data (the archived data, historical maps, topographic maps, and ground control points).

\section{Classification Accuracy Assessment}

Accuracy assessment method is very useful for individual classification when resulting data are used for the change detection analysis (OwojoriandXie2005). Accuracy assessment technique was performed based on using a random sample method of more than 150 check points i.e. ground control points, old sketch maps, topographic maps as a referenced map in ERDAS Imagine 9.2 software to scrutinize theland use or land cover classes of the area.

\section{Detection of LULC changes}

Post Classification Comparison (PCC) method and change detection analysis were applied to compare and analyze the LULC maps resulting from the integration of the results of visual interpretation and supervised classification. PCC was employed to detect the differences between each pair of LULC maps (i.e., 1980 to 1990,1990 to 2000, 2000 to 2010 and 2010 to 2015).

Fig.2. shows an overlay of RajpurSonarpur Municipality administrative boundaries in 1980,1990,2000,2010 and 2015. The total urban areas for the five respective periods were estimated at $8.21,10.80,15.92,21.67$ and 23.22 (Table 4). Analysis of annual rate of change between the four periods (1980-1990), (1990-2000), (2000-2010), (2010-2015) showed that the area expanded by $52.5 \%, 84.5 \%, 136.1 \%, 62.8 \%$ respectively, with an average rate of 84\% for the whole study period, from 1980 to 2015.

\section{Table 3. Identified Classes by Supervised Classification}

\begin{tabular}{|c|c|c|}
\hline No & Land Use Classes & Description \\
\hline 1 & Built-up Area & Residential, Commercial, Industrial, Roads, Railway, mixed urban or built-up area \\
\hline 2 & Vegetation & Vegetative areas, Agricultural areas \\
\hline 3 & Water body & Pond, Canal, Reservoir \\
\hline 4 & Fallow land & Waste land, Fallow land \\
\hline
\end{tabular}




\section{Change detection}

Following the classification of imagery from the individual years, a multi-date post-classification comparison change detection algorithm was used to determine changes in land use and land cover in four intervals, 1980-1990, 1990-2000, 2000-2010, and 2010-2015. This is perhaps the most common approach to change detection (Jensen 2004) and has been successfully used by (Yang 2002) to monitor land use changes in the Atlanta, Georgia area.

\section{Change detection accuracy assessment}

Change detection presents unique problems for accuracy assessment since it is difficult to sample areas that will change in the future before they change. A concern in change detection analysis is that both position and attribute errors can propagate through the number of multiple dates. This is especially true when more than the two dates are used in the analysis. The simplest method of accuracy assessment of change maps is to multiply the individual classification map accuracies to estimate the expected accuracy of the change map (Yuan et al. 1999). A more rigorous approach is to randomly sample areasclassified as change and no-change and determine whether they were correctly classified (Fuller et al. 2003).

Overall accuracy was calculated from the error matrix by dividing the sum of the entries that make major diagonal by the total number of examined pixels. Kappa co-efficient of agreement was also calculated by using following equations (Afify2011).

$$
\begin{gathered}
\hat{K}=p_{o}-p_{c} \div 1-p_{c} \\
P_{o}=\sum_{i=1}^{r} P_{i i} \\
P_{c}=\sum_{i=1}^{r} P_{i}+P+i
\end{gathered}
$$

Here,

$r=$ The number of rows in the error matrix.

Pii=The proportion of pixels in row 'i' and column ' $i$ '.

$\mathrm{Pi}+=$ The proportion of the marginal total of row 'i'.

$\mathrm{P}+\mathrm{i}=$ The proportion of the marginal total of column ' $\mathrm{i}$ '.

\section{RESULTS}

\section{Land use pattern in 1980}

To scrutinize the land use pattern in 1980, the researcher first tried to focus on the Landsat MSS imagery for the year 1980. Different land use categories had been identified and used as past reference for the year 1980. Those identified land use pattern was verified in the ground truth verification. Because Prior ground verification knowledge is crucial to recognize the pattern of land use classes during supervised image classification. By applying the ground truth knowledge the researcher identified the pixel along with their color tone, texture to verify each land use category during the classification of image. The land use pattern which were categorized into four classes for the year are listed in Table 3 and shown in Fig. 2A total of 49.26 Sq.km. of land area was estimated for this municipality after the supervised classification. From the identified land use categories, the highest category was vegetation (53\% of the total land area) and it is followed by fallow land (16.93\% of the total land area), built up area (16.67\% of the total land area) and waterbody (12\% of the total land area) shown in Table 4.

In figure 2a, brownish patches indicates built up area which was more prominent in this municipal areas. The yellow color indicates fallow land which was high in this time period. In the eastern side the percentage of fallow land is relatively high than the other areas (Fig. 2a).In this period the percentage of fallow land is relatively high than the other periods which is because of low resolution of the image.
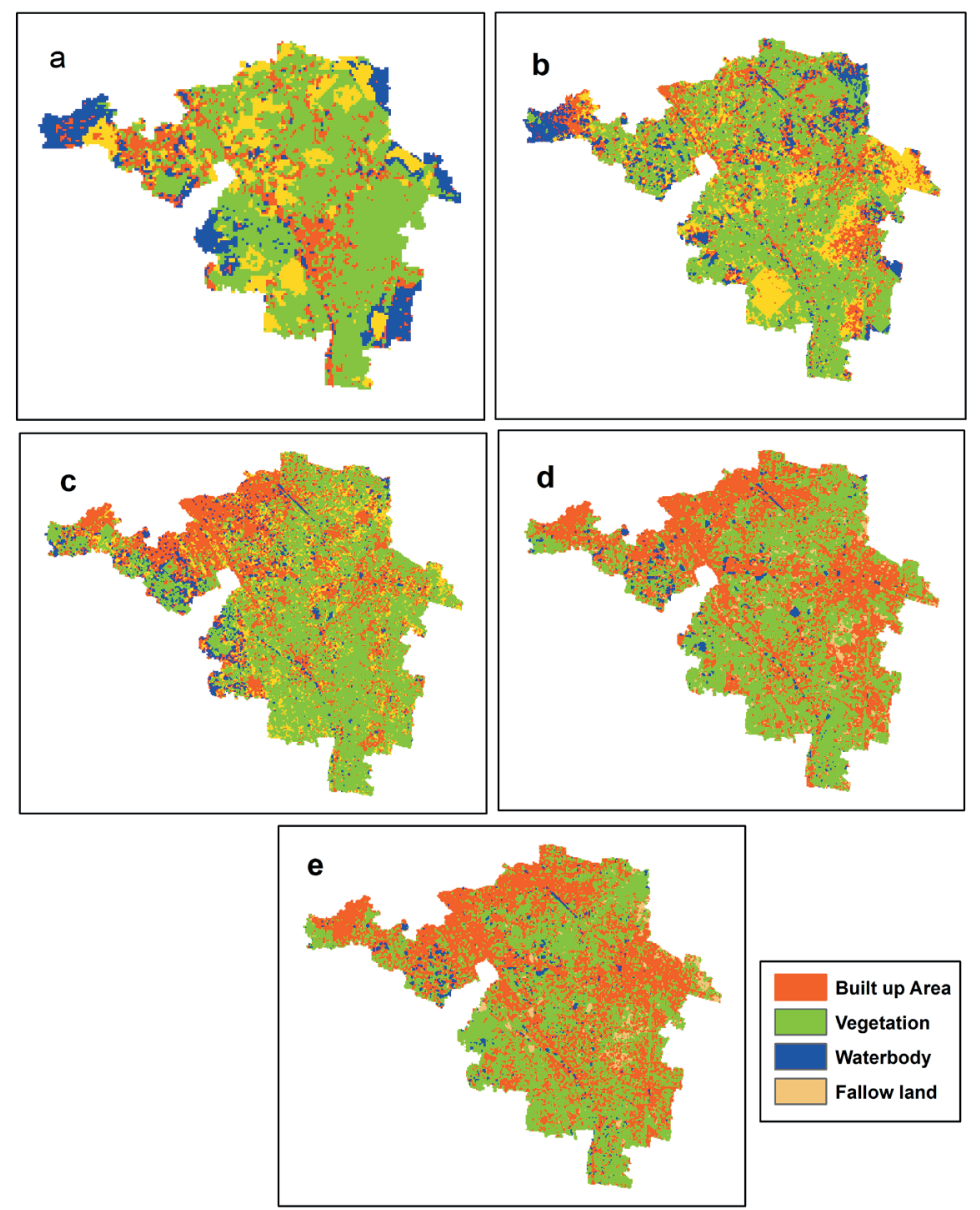

Fig. 2a. to 2e. LULC of RajpurSonarpur Municipality 1980-2015 


\section{Land use pattern in 1990}

After 1990 land use classification, land use pattern of 1990 (Fig. 2b) was visually interpreted.A total of 4 land use categories were identified during 1990 image classification. Based on 1990 image classification results, the highest category was vegetation (24.72 sq.km. sharing 50\% of total land area) followed by built up area, 10.80 sq.km. (22\%) and fallow land 7.89 sq.km. (16\%) and water body sharing 4.28 sq.km. (9\%) respectively (Table 3 and 4).Advantageous location of the municipality, nearness to adjacent railway station i.e. Sonarpur and Subhasgram railway station, good market facility, both type of well-connected roads (Metalled and arterial roads) and good infrastructure facility were the main causes behind the growth of built up area.

\section{Land use pattern in 2000}

In 2000 (Fig 2c), built up area covered 32\% of the study area, whereas vegetation, water bodies and fallow land accounted for $47 \%, 11 \%$ and $6 \%$ of the area respectively (Table 4). In this figurebuiltup area is high in the north west portion. It is relatively high than the other areas which are because of accessibility from the city core areas by the N.S.C. Bose road. Beside these factors metro railway is another factor behind the huge population density of the region.

After the year 1993 different mouzas were added under this municipality's jurisdiction. After the addition of those panchayats, it has seen that right side of the railway track is denser than the left side. Because left side portion of the railway track is already highly dense from the past years. Land use pattern in 2010 and 2015

In 2010 (Fig. 2d), vegetation area accounted for 45.92\% of the study area, whereas built up area, water bodies and fallow land covered $44.99 \%, 4.66 \%$ and $4.26 \%$ of the study area. But after the five years i.e. in the year 2015 (Fig. 2e), majority (47\%) of the study area was categorized as built up area and it is followed by vegetation, water bodies and fallow land i.e. 44\%, 2\% and 3\% respectively (Table 4).The observed difference of the LULC classes of RajpurSonarpur area as shown in Table 5.

\section{Relative Changes in Land Use in RajpurSonarpur}

Relative change in land uses (percentage) of this municipality was assessed based on data presented in Table 6. The relative changes showed some irregular pattern in this study area from 1980 to 2015. Land use change from 19802015 showed negative changes in most of the categories except the built up area.

Around $6 \%$ of Natural vegetated area had decreased between 1990 to 2000 time period,while 30\% of the wetlands or water bodies has been converted built up areas between these time period. Between the year 2000 to 2010 the percentage of Built up area has been increased into $36 \%$ while $55 \%$ of the wetlands or water bodies has been converted into fallow land or builtup area.In the year 2015, 32\% of the fallow landhas been decreased due to urban growth. These are the consequences of huge urban growth in this area.

\section{Classification and Change Detection Accuracy}

Error matrices were used to assess classification accuracy and are summarized for all five years in Table 7a-7e. The overall accuracies for 1980, 1990, 2000, 2010 and 2015 were, respectively, $92.5 \%, 85 \%, 87.5 \%, 90 \%$ and $92.5 \%$, with Kappa statistics of $87 \%, 77 \%, 78 \%, 81 \%$ and $86 \%$. Users and producer's accuracies of individual classes were consistently high, ranging from $85 \%$ to $92 \%$. Specially 1980 , the resolution of the image was very low. To minimize the errors of the image, post classification comparison has been done among the classified images of 1990 and 1980.

Table 4. Trend of Land use and Land cover (sq.km.) in RajpurSonarpur Municipality

\begin{tabular}{|c|c|c|c|c|c|}
\hline Year & 1980 & 1990 & 2000 & 2010 & 2015 \\
\hline Built up area & 8.21 & 10.80 & 15.92 & 21.67 & 23.22 \\
\hline Vegetation & 26.02 & 24.72 & 23.23 & 1.31 & 21.86 \\
\hline Waterbody & 6.14 & 4.28 & 2.96 & 2.10 & 1.21 \\
\hline Fallow land & 8.34 & 7.89 & 5.67 & 1.42 \\
\hline
\end{tabular}

Table 5. Trend of Land Use and Land Cover in RajpurSonarpur Municipality

\begin{tabular}{|c|c|c|c|c|c|c|c|c|c|}
\hline \multirow{2}{*}{ Year } & \multicolumn{4}{|c|}{ Percentage of Area in Sq.km } & \multicolumn{4}{c|}{ Changes of Area in Percentage } \\
\cline { 2 - 12 } & 1980 & 1990 & 2000 & 2010 & 2015 & $1980-1990$ & $1990-2000$ & $2000-2010$ & $2010-2015$ \\
\hline Built up area & 16.85 & 22.65 & 33.53 & 45.43 & 48.67 & 5.79 & 10.88 & 11.90 & 3.24 \\
\hline Vegetation & 53.42 & 51.83 & 48.93 & 47.42 & 45.82 & -1.58 & -2.91 & -1.50 & -1.60 \\
\hline Waterbody & 12.61 & 8.97 & 6.23 & 2.75 & 2.54 & -3.63 & -2.74 & -3.49 & -0.21 \\
\hline Fallow land & 17.12 & 16.54 & 11.94 & 4.40 & 2.98 & -0.58 & -4.60 & -7.54 & -1.43 \\
\hline
\end{tabular}

Table 6. Relative changes in the land use and land cover from 1980 to 2015

\begin{tabular}{|c|c|c|c|c|}
\hline \multirow{2}{*}{ Land Use Categories } & \multicolumn{4}{|c|}{ Changes in Area (Percentage) } \\
\cline { 2 - 5 } & $1980-1990$ & $1990-2000$ & $2000-2010$ & $2010-2015$ \\
\hline Built up area & 31.47 & 47.35 & 36.14 & 4.77 \\
\hline Vegetation & -4.99 & -6.04 & -2.61 & -3.35 \\
\hline Water body & -30.37 & -30.65 & -55.59 & -47.10 \\
\hline Fallow land & -5.42 & -28.06 & -62.86 & -32.39 \\
\hline
\end{tabular}


Table 7. Error matrix of LULC Classification

\begin{tabular}{|c|c|c|c|c|c|c|c|}
\hline \multicolumn{8}{|l|}{ Sub-table 7a } \\
\hline \multicolumn{8}{|c|}{ Error matrix showing accuracy and Kappa statistics of 1980 supervised land use classification } \\
\hline Reference Data & & & & & & PA (\%) & UA (\%) \\
\hline Classified Data & Built up Area & Vegetation & Water Body & Fallow Land & Total & & \\
\hline Built up Area & 9 & 0 & 0 & 0 & 9 & 100 & 100 \\
\hline Vegetation & 0 & 22 & 0 & 0 & 22 & 100 & 80 \\
\hline Water Body & 0 & 0 & 4 & 3 & 7 & 100 & 100 \\
\hline Fallow Land & 0 & 0 & 0 & 0 & 0 & 40 & 100 \\
\hline Total & 9 & 22 & 4 & 3 & 38 & & \\
\hline \multicolumn{8}{|c|}{ Overall Accuracy $=92.50 \%$, Kappa Statistics $=0.87$} \\
\hline \multicolumn{8}{|l|}{ Sub-table $7 b$} \\
\hline \multicolumn{8}{|c|}{ Error matrix showing accuracy and Kappa statistics of 1990 supervised land use classification } \\
\hline Reference Data & & & & & & PA (\%) & UA (\%) \\
\hline Classified Data & Built up Area & Vegetation & Water Body & Fallow Land & Total & & \\
\hline Built up Area & 7 & 2 & 0 & 2 & 11 & 78 & 63 \\
\hline Vegetation & 2 & 18 & 0 & 0 & 20 & 90 & 90 \\
\hline Water Body & 0 & 0 & 3 & 0 & 3 & 100 & 100 \\
\hline Fallow Land & 0 & 0 & 0 & 6 & 6 & 75 & 100 \\
\hline Total & 9 & 20 & 3 & 8 & 40 & & \\
\hline \multicolumn{8}{|c|}{ Overall Accuracy $=85 \%$, Kappa Statistics $=0.77$} \\
\hline \multicolumn{8}{|l|}{ Sub-table 7c } \\
\hline \multicolumn{8}{|c|}{ Error matrix showing accuracy and Kappa statistics of 2000 supervised land use classification } \\
\hline Reference Data & & & & & & PA (\%) & UA (\%) \\
\hline Classified Data & Built up Area & Vegetation & Water Body & Fallow Land & Total & & \\
\hline Built up Area & 0 & 0 & 0 & 2 & 2 & 87 & 87 \\
\hline Vegetation & 13 & 0 & 0 & 1 & 14 & 100 & 87 \\
\hline Water Body & 2 & 20 & 1 & 0 & 23 & 100 & 100 \\
\hline Fallow Land & 0 & 0 & 0 & 1 & 1 & 25 & 100 \\
\hline Total & 15 & 20 & 1 & 4 & 40 & & \\
\hline \multicolumn{8}{|c|}{ Overall Accuracy $=87.50 \%$, Kappa Statistics $=0.78$} \\
\hline \multicolumn{8}{|l|}{ Sub-table $7 d$} \\
\hline \multicolumn{8}{|c|}{ Error matrix showing accuracy and Kappa statistics of 2010 supervised land use classification } \\
\hline Reference Data & & & & & & PA (\%) & UA (\%) \\
\hline Classified Data & Built up Area & Vegetation & Water Body & Fallow Land & Total & & \\
\hline Built up Area & 18 & 2 & 0 & 0 & 20 & 95 & 90 \\
\hline Vegetation & 1 & 17 & 1 & 0 & 19 & 90 & 90 \\
\hline Water Body & 0 & 0 & 0 & 0 & 0 & - & - \\
\hline Fallow Land & 0 & 0 & 0 & 1 & 1 & 100 & 100 \\
\hline Total & 19 & 19 & 1 & 1 & 40 & & \\
\hline \multicolumn{8}{|c|}{ Overall Accuracy $=90 \%$, Kappa Statistics $=0.81$} \\
\hline \multicolumn{8}{|l|}{ Sub-table 7e } \\
\hline \multicolumn{8}{|c|}{ Error matrix showing accuracy and Kappa statistics of 2015 supervised land use classification } \\
\hline Reference Data & & & & & & PA (\%) & UA (\%) \\
\hline Classified Data & Built up Area & Vegetation & Water Body & Fallow Land & Total & & \\
\hline Built up Area & 0 & 3 & 0 & 0 & 3 & 100 & 87 \\
\hline Vegetation & 19 & 17 & 0 & 0 & 36 & 85 & 100 \\
\hline Water Body & 0 & 0 & 1 & 0 & 1 & 100 & 100 \\
\hline Fallow Land & 0 & 0 & 0 & 0 & 0 & - & 0 \\
\hline Total & 19 & 20 & 1 & 0 & 40 & & \\
\hline \multicolumn{8}{|c|}{ Overall Accuracy $=92.50 \%$, Kappa Statistics $=0.86$} \\
\hline
\end{tabular}




\section{Classification and Change Maps and Statistics}

Change detection maps were generated for all five years (Fig. $3 a$ to $3 d$ ) and the individual class area and change statistics for the five years are summarized in Table 4 and Table 5.

From 1980 to 2015, urban area increased approximately 15.01 Sq.km. while vegetation area decreased 4.17 Sq.km. (\%), water body 4.93 Sq.km., and fallow landdecreased 6.92 Sq.km. Relatively, urban and developed areas increased 8.21 Sq.km. to 23.22 Sq.km. from 1980 to 2015, with the greatest increase occurring from 1990 to 2000 i.e. $47 \%$ of the total change, while vegetation, water bodies and wetland decreased, respectively, 6\%, 30\% and 28\%.But changes in vegetation, water bodies and fallow land was intensive from the year 2000 to 2010 i.e. $1.50 \%, 3.49 \%$ and $7.54 \%$ respectively (Table 5). To reduce this error image correction techniques was used. To further evaluate the results of land cover conversions, matrices of land cover changes from 1980 to 1990,1990 to 2000, 2000 to 2010, and 2010 to 2015 were created (Table 8a to 8d).In the table, unchanged pixels are located along the major diagonal of the matrix. Conversion values were sorted by area.These results indicate thatincreases in urban areas mainly came from conversion ofvegetated land and water bodies to urban uses during the twenty five year period,1980-2015(Table 8a to 8d).

From 2000 to 2010, 7.32 Sq.km. was converted fromvegetated area and 2.97 Sq.km. from fallow land. While in 2010 to 2015,5.26 sq.km area was converted into built up area from the vegetated area, while at the same time, some portionof urban area was converted to forest. These changes may seem tobe classification errors. But vegetated areas are among some of the most sought after areas for developing new housing. Roads and railway lines were generally classified as urban, but when urban trees along the streets grow and expand, the associated pixels may be classified as vegetation. The researcher note that the changes from urban to forest occurred almost entirely near city streets and railway. This same thing also happened in some cases of water body areas. Because some time it falls under the vegetation areas because of the cover by hydrophytes. Classification errors may also cause other unusual changes.

In Table 8the researcher examines more specifically the changes in cover type between 1980 and 2015 for the random sample of the correctly classified 200 change samples from the 300change sites evaluated. Maximum percentage of land use change was «vegetation to urban» and «water bodies to urban». These percentages of change are similar to the results of the change detection from the Landsat classifications of the entire area. Relatively rare and unlikely types of conversions, such as fallow land to water body, and then to urban areas and urban to vegetation, and then to urban area, totaling $5 \%$, are assumed to largely be classification errors.

\section{Table 8. Matrices of LULC changes from 1980-2015}

\begin{tabular}{|c|c|c|c|c|c|}
\hline \multicolumn{6}{|c|}{ Matrices of Land Cover and Changes (Sq.Km.) from 1980 to 1990} \\
\hline \multirow{2}{*}{$\begin{array}{c}\text { a. } 1980-1990 \\
1990\end{array}$} & \multicolumn{5}{|c|}{1980} \\
\hline & Built up Area & Vegetation & Water Body & Fallow Land & 1990 Total \\
\hline Built up Area & 1.84 & 0 & 0.7 & 0.8 & 10.81 \\
\hline Vegetation & 5.18 & 14.66 & 1.44 & 4.33 & 24.73 \\
\hline Water Body & 1.55 & 1.93 & 1.41 & 0.91 & 4.28 \\
\hline Fallow Land & 2.21 & 3.37 & 0.71 & 1.84 & 7.89 \\
\hline 1980 Total & 8.22 & 26.03 & 6.15 & 8.34 & 49.26 \\
\hline \multicolumn{6}{|c|}{ Matrices of Land Cover and Changes (Sq.Km.) from 1990 to 2000} \\
\hline \multirow{2}{*}{$\begin{array}{l}\text { b. } 1990-2000 \\
2000\end{array}$} & \multicolumn{5}{|c|}{1990} \\
\hline & Built up Area & Vegetation & Water Body & Fallow Land & 2000 Total \\
\hline Built up Area & 5.42 & 3.55 & 0.33 & 1.44 & 15.92 \\
\hline Vegetation & 5.9 & 15.25 & 1.23 & 2.21 & 23.24 \\
\hline Water Body & 1.1 & 1.83 & 0.88 & 0.42 & 2.97 \\
\hline Fallow Land & 2.4 & 3.75 & 0.12 & 1.57 & 5.68 \\
\hline 1990 Total & 10.81 & 24.73 & 4.28 & 7.89 & 49.26 \\
\hline \multicolumn{6}{|c|}{ Matrices of Land Cover and Changes (Sq.Km.) from 2000 to 2010} \\
\hline \multirow[t]{2}{*}{$\begin{array}{c}\text { c. } 2000-2010 \\
2010\end{array}$} & \multicolumn{5}{|c|}{2000} \\
\hline & Built up Area & Vegetation & Water Body & Fallow Land & 2010 Total \\
\hline Built up Area & 10.84 & 3.53 & 0.14 & 0.46 & 21.68 \\
\hline Vegetation & 7.32 & 15.91 & 0.92 & 0.93 & 22.63 \\
\hline Water Body & 0.55 & 1.27 & 0.76 & 0.03 & 1.32 \\
\hline Fallow Land & 2.97 & 1.92 & 0.09 & 0.7 & 2.11 \\
\hline 2000 Total & 15.92 & 23.24 & 2.97 & 5.68 & 49.26 \\
\hline
\end{tabular}




\begin{tabular}{|c|c|c|c|c|c|}
\hline \multicolumn{6}{|c|}{ Matrices of Land Cover and Changes (Sq.Km.) from 2010 to 2015} \\
\hline \multirow{2}{*}{$\begin{array}{c}\text { d. } 2010-2015 \\
2015\end{array}$} & \multicolumn{5}{|c|}{2010} \\
\hline & Built up Area & Vegetation & Water Body & Fallow Land & 2015 Total \\
\hline Built up Area & 16.9 & 4.19 & 0.19 & 0.39 & 23.23 \\
\hline Vegetation & 5.26 & 16.34 & 0.39 & 0.64 & 21.87 \\
\hline Water Body & 0.23 & 0.41 & 0.64 & 0.04 & 1.21 \\
\hline Fallow Land & 0.83 & 0.93 & 0 & 0.35 & 1.42 \\
\hline 1990 Total & 21.68 & 22.63 & 1.32 & 2.11 & 49.26 \\
\hline
\end{tabular}

\section{DISCUSSION}

Although similar statistics could be generated for other units suchas county, township, or census tract, etc., the above change statistics shed little light on the question of where land use changes are occurring. However, by constructing a change detection map (Fig. 3a to $3 d$ ), the advantages of satellite remote sensing in spatially disaggregating the change statistics can be more fully appreciated. Fig. 3a to 3eshows a map of the major land cover types and the conversion from semi urban to urban uses. Built up area, vegetation and water bodies representing maximum percentage of the total area, are the three major land cover types in this municipality.Conversions involving these three classes also represent the most significant changes. Urban growth and the loss of vegetation land were the most important conversions in this area. Although Fig. 3a to 3eonly displays the changes from vegetation, water bodies and fallow land to urban, other changes can also be mapped. The urban growth occurred to the west (Harinavi area), towards eastern side (towards the railway station), and south (Subhashgram railway station area) directions. Whereas growth towards the northern side was limited by the influence of Kolkata Municipal Corporation (Fig. 1). The southward expansion and the westward expansion was the highest and is attributed to the presence of the Sonarpur and Subhashgram railway station and because of the availability of abundant flat vacant land which was suitable for housing construction. A major road named Eastern Metropolitan By pass connecting the airport with Kolkata city is also passing through the RajpurSonarpur Municipality in this area.

In summary, information from satellite remote sensing can play a significant role in quantifying and understanding the nature of changes in land cover and where they are occurring. Such information is essential to planning for urban growth and development.

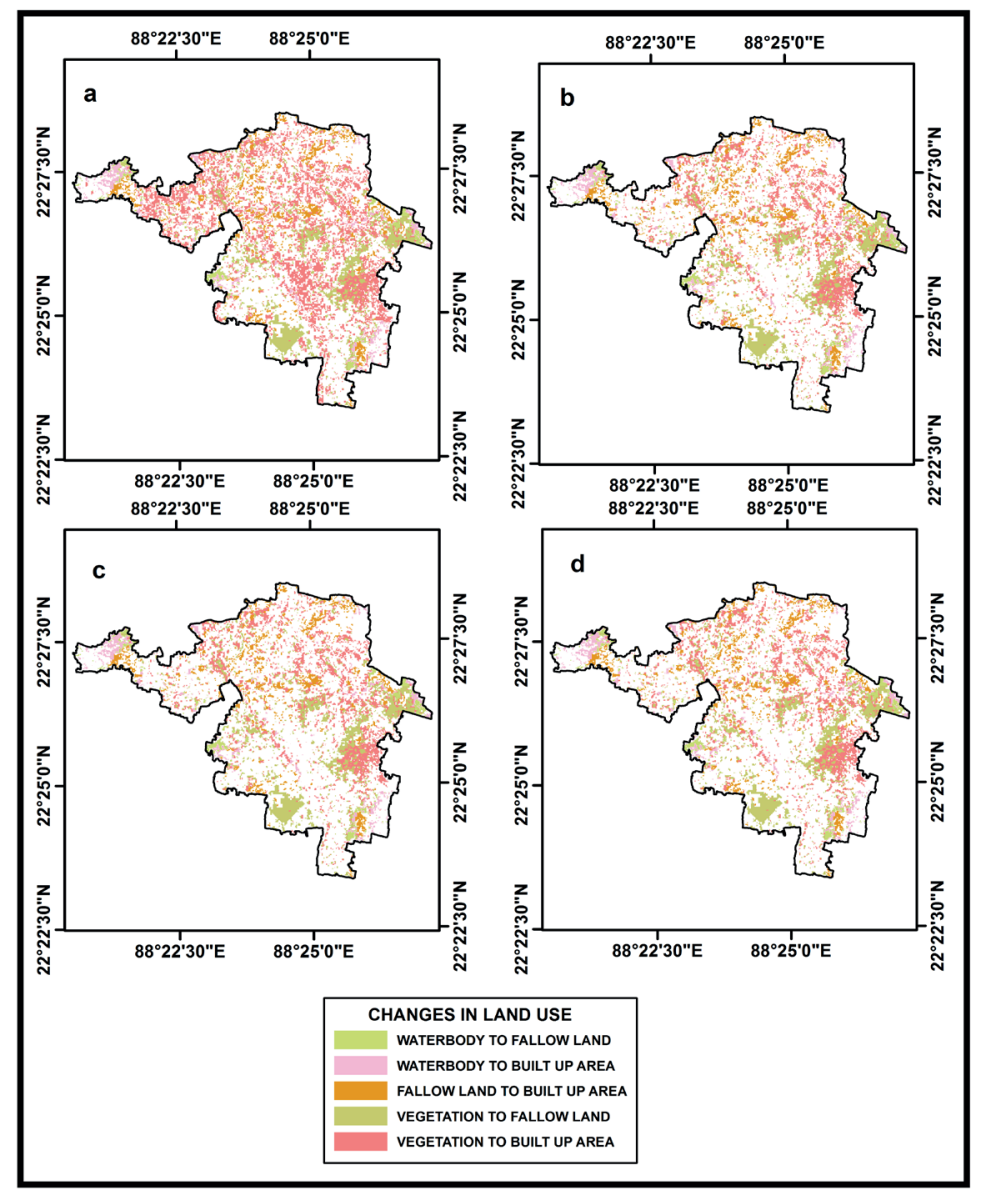

Fig. 3a. to 3d. showing changes in the LULC from 1980 to 2015; Fig. 3a showing the changes of land use between 1980 to 1990 , Fig. 3b showing the changes of land use between 1990 to 2000, Fig. 3c showing the changes of land use between 2000 to 2010, Fig. 3d showing the changes of land use between 2010 to 2015 
Fig. 3a to 3d showing changes in the LULC from 1980 to 2015; Fig. 3a showing the changes of land use between 1980 to 1990, Fig. 3b showing the changes of land use between 1990 to 2000, Fig. 3c showing the changes of land use between 2000 to 2010, Fig. 3d showing the changes of land use between 2010 to 2015.

\section{CONCLUSION}

The objective of the study were to provide multitemporal land cover map and its change analysis in the last twenty five years. The study area has undergone a very severe land cover changes as a result of large residential projects and good infrastructural facilities. It leads into high population growth which results into the increases in built up areas. Due to this reason vegetation, wetland and fallow land decreases rapidly. This also demonstrates that supervised classifications of the landsat imageries can be used to produce accurate landscape change maps and future planning of the area. General patterns and trends of land use change in RajpurSonarpur Municipal Area were evaluated by: (1) classifying the land, it has been found that agricultural tracts, vegetation and wetland were converted into urban land during the periods from 1980 to 2015; (2) comparing the results of multi temporal Landsatderived statistics to estimates from other inventories; (3) quantitatively assessing the accuracy of change detection maps by kappa statistics or khat statistics. By this study the changes and pattern of land use and land cover has been identified. After land use and land cover analysis, it has been found that most of the land use and land cover in this area has been transformed in to urban area or built up area in this time period which creates extreme pressure in the local land resources and ecosystem. This study will help to identify the major urban land use change patterns in relation to policy making and planning, transportation and population growth for the sustainable development of the area. The results quantify the land cover change patternsof this municipal area and demonstrate the potential of multi temporal Landsat data to provide an accurate, economical means to map and analyze changes in land cover over time that can be used as inputs to land management and policy decisions.

\section{REFERENCES}

Afify H.A. (2011). Evaluation of change detection techniques for monitoring landcoverchanges: a case study in new Burg El-Arab area. Alexandria Eng. J. 50, 187-195, DOI: 10.1016/j.aej.2011.06.001.

Adamo S.B. and Crews-Meyer K.A. (2006). Aridity and desertification: exploring environmental hazards in Jáchal, Argentina. Applied Geography, 26(1), 61-85.

Batisani N. and Yarnal B. (2009). Urban expansion in Centre County, Pennsylvania: spatial dynamics and landscape transformations. Applied Geography, 29(2), 235-249.

Blodget H., Taylor P. and Roark J. (1991). Shoreline changes along the Rosetta-NilePromontory: monitoring with satellite observations. Marine Geology, 99, 67-77.

Campbell J.B. (1987). Introduction to remote sensing. The Guilford Press.

Cihlar J. (2000). Land cover mapping of large areas from satellites: status andresearchpriorities. International Journal of Remote Sensing, 21, 1093-1114.

Chan J.C., Chan K.P. and Yeh A.G.O. (2001). Detecting the nature of change in an urbanenvironment: A comparison of machine learning algorithms. Photogrammetric Engineering and Remote Sensing, 67, 213-225.

Chen X., Vierling L. and Deering D. (2005). A simple and effective radiometric correctionmethod to improve landscape change detection across sensors and across time. Remote Sensing of Environment, 98(1), 63-79.

Cohen W.B., Fiorella M., Gray J., Helmer E., Anderson K. (1998). An efficient and accurate method for mapping forestclearcuts in the Pacific Northwest using Landsat imagery. Photogrammetric Engineering and Remote Sensing 64, 93-300.

Coppin P., Jonckheere I., Nackaerts K., Muys B. and Lambin E. (2004). Digital change detection methods inecosystem monitoring: a review. International Journal of Remote Sensing, 25(9), 1565-1596.

Dewan A.M. and Yamaguchi Y. (2009). Land use and land cover change in Greater Dhaka, Bangladesh: using remote sensing to promote sustainable urbanization. Applied Geography, 29(3), 390-401.

Dong Y., Forster B. and Ticehurst C. (1997). Radar backscatter analysis for urban environments. International Journal of Remote Sensing, 18(6), 1351-1364.

Eastman J.R., McKendry J., Fulk M.A. (2005). Change and time series analysis. In: Explorations in Geographic Informations Systems Technology, United Nations Institute for Training and Research (UNITAR), Geneva.

Fuller R.M., Smith G.M. and Devereux B.J. (2003). The characterization and measurement of land cover change through remote sensing: Problems in operational applications. International Journal of Applied Earth Observation and Geoinformation, 4, 243-253.

Gao J. and Liu Y. (2010). Determination of land degradation causes in Tongyu County,NortheastChina via land cover change detection. International Journal of Applied Earth Observation and Geoinformation, 12(1), 9-16.

Giri C., Zhu Z. and Reed B. (2005). A comparative analysis of the Global Land Cover 2000 and MODIS landcover data sets. Remote Sensing of Environment, 94, 123-132.

Foody G.M. and Boyd D.S. (1999). Detection of partial land cover change associated with the migration ofinner-class transitional zones. International Journal of Remote Sensing, 20, 2723-2740.

IGBP. (1999). Land-Use and Land-Cover Change (LUCC) implementation strategy. IGBP Report No. 48/IHDP Report No 10. Stockholm (Sweden): International Geosphere-Biosphere Programme (IGBP) e International Human Dimension Programme on Global Environmental Change (IHDP).

Imbernon J. (1999). Changes in agricultural practice and landscape over a 60-yearperiod in North Lampung, Sumatra. Agriculture, Ecosystems and Environment, 76(1), 61-66.

Jensen J.R. (1996). Introductory digital image processing: A remote sensing perspective. Upper Saddle, NJ: Prentice-Hall.

Jensen J.R., Hodgson M.E., Tullis J.A. and Raber G.T. (2004). Remote sensing ofimpervious surfaces and building infrastructure. In R.R. Jensen, J.D. Gatrell (eds.). Geospatial Technologies in Urban Environments: Policy, Practice in Heidelberg, 5-20.

Johnson R.D., Kasischke E.S. (1998). Change vector analysis: a technique for the multispectral monitoring of land cover and condition. International Journal of Remote Sensing 19, 411-426. 
Khorram S., Biging G.S., Chrisman N.R., Congalton R.G., Dobson J.E., Ferguson R.L. et al. (1999). Accuracy assessment of remote sensingderived change detection. Bethesda: American Society of Photogrammetryand Remote Sensing.

Lambin E.F., Geist H. and Lepers E. (2003). Dynamics of land use and cover change I tropical regions. Annual Review of Environment and Resources, 28, 205-241.

Lenney M.P., Woodcock C.E., Collins J.B. and Hamdi H. (1996). The status of agricultural lands in Egypt: The use of multi temporal NDVI features derived from Landsat TM. Remote Sensing Environment, 56, 8-20.

Lillesand T.M. and Kiefer R.W. (1994). Remote sensing and image interpretation (4thed.) New York: Wiley.

Long-qian C., Li W. and Lin-shan Y. (2009). Analysis of urban landscape pattern change in Yanzhou city based on TM/ETM+ images. Procedia: Earth and Planetary Science, 1(1), 1191-1197.

Lu D., Mausel P., Brondizio E. and Moran E. (2004). Change detection techniques. InternationalJournal of Remote Sensing, 25(12), 23652407.

Lu D.S., Mausel P., Batistella M., Moran E. (2005). Land-cover binary change detection methods for use in the moist tropical region of the Amazon: a comparative study. International Journal of Remote Sensing 26, 101-114.

Majumdar S. (2020). Land Suitability Analysis for Peri-urban Agriculture Using Multi-criteria Decision Analysis Model and Crop Condition Monitoring Methods: A Case Study of Kolkata Metropolitan Area. In: Pattnaik P., Kumar R., Pal S., Panda S. (eds) loT and Analytics for Agriculture. Studies in Big Data, 63, Springer, Singapore.

Majumdar S., Sivaramakrishnan L. (2020). Mapping of Urban Growth Dynamics in Kolkata Metropolitan Area: A Geospatial Approach. In: Bandyopadhyay S., Pathak C., Dentinho T. (eds) Urbanization and Regional Sustainability in South Asia. Contemporary South Asian Studies. Springer, Cham.

Mendoza J.E. and Etter R. (2002). Multi-temporal analysis (1940-1996) of land cover changes in the south western Bogota high plain (Colombia). Landscape and Urban Planning, 59(3), 147-158.

Mouflis G.D., Gitas I.Z., Iliadou S. and Mitri G.H. (2008). Assessment of the visual impact of marble quarry expansion (1984-2000) on the landscape of Thasos island, NE Greece. Landscape and Urban Planning, 86(1), 92-102.

Muchoney D.M. and Haack B. (1994). Change detection for monitoring forest defoliation. Photogrammetric Engineering and Remote Sensing, 60, 1243-1251.

Mukhopadhyay A., Mukherjee S., Garg R. and Ghosh T. (2013). Spatio-temporal analysis of land use-landcoverchanges in Delhi using remote sensing and GiS techniques.International Journal of Geomatics and Geosciences, 4(1), 213-223.

Munroe D.K., Croissant C. and York A.M. (2005). Land use policy and landscape fragmentation in an urbanizing region: assessing the impact of zoning. Applied Geography, 25(2), 121-141.

Nagendra H., Pareeth S. and Ghate R. (2006). People within parks-forest villages, land-cover change and landscape fragmentation in the TadobaAndhari Tiger Reserve, India. Applied Geography, 26(2), 96-112.

Owojori A. and Xie H. (2005). Landsat image-based LULC changes of San Antonio, Texas using Advanced atmospheric correction and Object-oriented image analysis Approaches. Paper presented at the 5th International Symposium on Remote Sensing of Urban Areas, Tempe, AZ.

Palmer A.R. and Van Rooyen A.F. (1998). Detecting vegetation change in the southern Kalahari using LandsatTM data. Journal of Arid Environments, 39, 143-153.

Ram B. and Kolarkar A.S. (1993). Remote sensing application in monitoring land-use changes in arid Rajasthan.International Journal of Remote Sensing, 14(17), 3191-3220.

Roy D.P., Lewis P.E. and Justice C.O. (2002). Burned area mapping using multi-temporal moderate spatial resolution data-a bi-directional reflectance model-based expectation approach. Remote Sensing of Environment, 83, 263-286.

Rembold F., Carnicelli S., Nori M. and Ferrari A. (2000). Use of aerial photographs, landsatTM imagery andmultidisciplinary field survey for land-cover change analysis in the lakes region (Ethiopia). InternationalJournal of Applied Earth Observation and Geoinformation, 2(3-4), 181-189.

Sadek S.H.A. (1993). Use of landsat imagery for monitoring agricultural expansion of East and West Nile Delta, Egypt. Egyptian Journal of Soil Sciences, 33(1), 23-24.

Sankhala S., Singh B. (2014). Evaluation of urban sprawl and land use land cover change using remote sensing and GIS techniques: a case study of Jaipur City, India. Int. J. Emerging Technol. Adv. Eng. 4(1), 66-72.

Schulz J.J., Cayuela L., Echeverria C., Salas J. and Rey Benayas J.M. (2010). Monitoring land cover change of the dryland forest landscape of Central Chile (1975-2008). Applied Geography, 30(3), 436-447.

Serra P., Pons X. and SauríD. (2008). Land-cover and land-use change in a Mediterraneanlandscape: a spatial analysis of driving forces integrating biophysical and human factors. Applied Geography, 28(3), 189-209.

Shalaby A., AboelGhar M. and Tateishi R. (2004). Desertification impact assessment in Egypt using low resolution satellite data and GIS. The International Journal of Environmental Studies, 61(4), 375-384.

Shalaby A. and Tateishi R. (2007). Remote sensing and GIS for mapping and monitoring landcover and land-use changes in the North western coastal zone of Egypt. Applied Geography, 27(1), 28-41.

Singh A. (1989). Digital change detection techniques using remotely sensed data. International Journal of RemoteSensing, 10, 9891003.

Squires G.D. (2002). Urban Sprawl and the Uneven Development of Metropolitan America. In Gregory D. Squires (Ed.), Urban sprawl: Causes, consequences, and policy responses, Washington, D.C.:Urban Institute Press, 1-22.

Stow D.A., Chen D.M. and Parrott R. (1996). Enhancement, identification and quantification of land cover change. In Morain S.A. and Lopez Barose S.V. (Eds.), Raster imagery in geographical information systems. Santa Fe: One Word, 307-312.

Thomas I.L., Benning V.M. and Ching N.P. (1987). Classification of remotely sensed images. Bristol: Adam Hilger.

Toll D.L., Royal J. and Davis J.B. (1980). Urban areas update procedures using Landsat data. In Proceedings ofAmerican Society of Photogrammetry. Falls Church, VA: American Society of Photogrammetry.

Townshend J.R.G. and Justice C.O. (1995). Spatial variability of images and the monitoring of changes in the normalized difference vegetation index.International Journal of Remote Sensing, 16, 2187-2195.

Yang X. and Lo C. (2002). Using a time series of satellite imagery to detect land use and land cover changes in the Atlanta, Georgia metropolitan area. InternationalJournalof Remote Sensing, 23(9), 1775-1798. 
Yuan D., Elvidge C.D. and Lunetta R.S. (1999). Survey of multi-spectral methods for land cover changeanalysis. In R.S. Lunettaand C.D. Elvidge (Eds.), Remote sensing change detection: Environmental monitoringmethods and applications. London: Taylor and Francis, 21-39.

Wyman M.S. and Stein T.V. (2010). Modeling social and land-use/land-cover change data to assess drivers of smallholder deforestation in Belize. Applied Geography, 30(3), 329-342.

Zhang B.P., Yao Y.H., Cheng W.M., Zhou C H., Lu Z. and Chen X.D. (2002). Human induced changes to biodiversity and alpine pastureland in the Bayanbulak Region of the East Tianshan Mountains. Mountain Research and Development, 22, 1-7. 